\title{
Escribir contra las cuerdas:La escritura académica, dispositivo de subjetivación
}

Fecha de recepción: 25 de agosto de 2018

Fecha de aprobación: 15 de diciembre de 2018

\section{Resumen}

Este texto se ocupa de la escritura académica como mecanismo de control del saber tecnocientífico. Analiza algunos rasgos distintivos del artículo científico, en tanto tipo textual dominante de las publicaciones académicas, y su función como dispositivo de subjetivación entre docentes e investigadores universitarios. Desde una lógica analítica que considera la antinomia apertura/cierre de la escritura, discute los patrones de diseño, producción y distribución de los textos académicos en las actuales condiciones de mercantilización de los saberes, y muestra cómo el aparataje normativo de estas formas textuales deviene sumisión y docilidad de la escritura y del sujeto que la produce. El análisis muestra al artículo científico como una forma "cerrada" y distópica de la escritura que, en el campo de las humanidades, parece contradecir su función heurística y creativa en la construcción e interpretación de lo social. Por último, llama la atención de escritores e investigadores en el campo de las humanidades para defender y resituar, desde la escritura misma, formas alternativas que resistan la instrumentalización extrema y la experimenten también como apertura, acontecimiento y devenir.

Palabras clave: escritura académica, discurso social, dispositivo, subjetivación.

Citar: Baquero, P. \& Martínez, J.E. (enero-junio de 2019). Escribir contra las cuerdas:La escritura académica, dispositivo de subjetivación. La Palabra, (34), 145-159. (i) https://doi.org/10.19053/01218530.n34.2019.9540

\section{Pedro Baquero M}

Magíster en Docencia, profesor Universidad Distrital FJC, doctorando en Estudios Sociales UDFJC

pbaquerorama@gmail.com

\section{Jorge E. Martínez P}

Doctor en Filosofía programa Historia de la Subjetividad. U. Barcelona. Doctor en Ciencias Sociales. Niñez y Juventud. Pos doctor en Filosofía Universidad de Cádiz. Profesor titular de la universidad de la Salle.

* Artículo de investigación. 


\section{la palabra}

\section{Writing against the Wall: Academic Writing as a Subjectivity Instrument}

This paper addresses the academic writing as an oversight mechanism regarding technic and scientific discourse. Additionally, it analyzes defining features of scientific papers on the point of its dominance in academic publications and its function as a subjectivity instrument among university professors and researchers. From the antinomy of writing opening/closing in an analytic logic, it discusses the creation's patterns, production and distribution of the academic papers in current conditions when facing knowledge commodification. Furthermore, it shows how the academic guidelines policies generate writing's suppression and submissiveness. This analysis presents the academic paper as a "closed" and dystopic way of writing in humanities, that seems to contradict its heuristic and creative function when building and interpreting social matters. Finally, it attracts humanities writers and researchers' attention to defend and relay, from the writing itself, in alternative ways to resist an extreme instrumentalization of writing.

Keywords: academic writing, social discourse, instrument, subjectivation.

La escritura y la escritura académica: apertura y cierre

Dado que no es la pretensión de este texto hacer un tratado sobre la escritura ni sobre la escritura académica, baste para los límites del artículo y de este primer apartado señalar, desde las antinomias de apertura $\mathrm{y}$ cierre, algunos de sus rasgos y caracterizaciones, tomados de fuentes diversas que podrían parecer, incluso, heterodoxas; pero que se avienen con la dinámica enunciativa de este escrito y con sus lógicas de argumentación.

Marcar la diferencia entre escritura y escritura académica como realizaciones del lenguaje, nos sirve, en este ejercicio, para destacar esa condición bifronte e incluso multiforme del mismo que también se pue- de advertir en la escritura, en su simultaneidad de apertura y cierre. En la primera manifestación, como fuerza irreductible y expresión del enorme potencial productivo y creativo del pensamiento, como acontecimiento en la historia y en la elaboración de la cultura (Ong, 1999), tal cual la conocemos en el presente; y en la creación de paradójicos "mundos posibles", gracias a su poder performativo, figurativo y representacional; y en la segunda, como una línea de segmentariedad dura, según lo proponen Deleuze-Guattari (2002) y que para el caso se manifestaría en las actuales formas de la escritura académica como dispositivo tecnocientífico (Ortiz, 2015) del actual modo de producción capitalista.

Desde una lógica "abierta" o descentrada del signo saussureano, la escritura desborda los límites de la semántica, no solo es estructura, no solo es función; es pragmática y performatividad, pues produce subjetividades y en el caso de la educación, en la que la escritura académica es un correlato, su fuerza performativa toca profundamente los cuerpos y las vidas de los profesores universitarios inducidos, entre otros aspectos, a pensarse a sí mismos en función de su productividad académica, del número de publicaciones indexadas y del volumen y valor de los reconocimientos que se les ofrecen en tanto contribuyen a satisfacer las demandas de "la lucha por la perceptibilidad: la base de datos, la reunión evaluativa, la reseña anual, la redacción de informes, la publicación regular de resultados y solicitudes de ascenso, las inspecciones e informes de pares" (Ball, 2003, p. 93), que constituyen, hoy por 
hoy, más allá de la docencia y la investigación mismas, la mayor preocupación de profesores e instituciones para hacerse visibles, competir, mantenerse y beneficiarse del nuevo y floreciente mercado educativo que constituye el verdadero vector de las otras tecnologías políticas educativas.

La analítica que Ball despliega para el estudio de la performatividad, se propone como una descomposición de un nuevo discurso de poder de sus "resistencias y acomodaciones", en las que no solo se revela la subjetividad, sino también los modos de regulación y funcionamiento de las organizaciones en las que el poder se desplaza del espacio-tiempo de los sistemas de producción como fábricas u oficinas hacia "las bases de datos, la evaluación anual, la elaboración de informes y los formularios para la promoción, las inspecciones, la evaluación de pares" (pp. 104-105), como formas discursivas institucionales que instauran la legitimidad y desde cuyas "fabricaciones" según define Butler (1993) al sistema de signos corporales y discursivos, se reasegura el valor de verdad cuyo fin último no es la verdad en sí misma, sino su efectividad en el mercado o en el gerenciamiento de la imagen. De esta manera, la performatividad puesta en el discurso institucional, "fabrica" sujetos y verdades.
La escritura en su conexión con el dispositivo, es tecnología de la palabra, un artificio "que ha moldeado e impulsado la actividad intelectual del hombre moderno" (Ong, 1999, p. 86), un puente tendido entre la proximidad y la distancia, es la red que hace posible, entre otras múltiples y quizá dicotómicas funciones, la abstracción, la reflexión, la prolongación de la memoria, la consolidación de los grafolectos modernos y con ellos los dispositivos de saber-poder, la hegemonía de los sistemas de pensamiento letrados, que ya advertía Rama en La ciudad letrada (1984); con sus grandes religiones, sus humanismos, su colonialidad en sus distintas manifestaciones; sus epistemocentrismos y egocentrismos, al igual que la objetivación del mundo y del sujeto: sus pliegues, sus formas de subjetivación y de repliegue $y$, en fin, todas aquellas dimensiones que hacen de la escritura una función dominante en el dispositivo de Foucault (1983), al que define como el conjunto de "instituciones, disposiciones arquitectónicas, decisiones reglamentarias, leyes, medidas administrativas, enunciados científicos; proposiciones filosóficas, morales, filantrópicas; tanto lo dicho como lo no dicho son elementos del dispositivo, y el dispositivo mismo es la red que puede establecerse entre esos elementos" (p. 184).
Pero si bien la escritura es parte constituyente del dispositivo y este, a su vez, es mecanismo de gubernamentalidad, la escritura también es acontecimiento, no solo por su trascendencia histórica, sino por su naturaleza interpretativa y figurativa del mundo como experiencia del sujeto:

Escribir es un asunto de devenir, siempre inacabado, siempre en curso, y que desborda cualquier materia vivible o vivida. Es un proceso, es decir un paso de Vida que atraviesa lo vivible y lo vivido. La escritura es inseparable del devenir; escribiendo, se deviene-mujer, se deviene-animal o vegetal, se deviene-molécula hasta devenir-imperceptible. (Deleuze, s.f., párr. 1).

En este último sentido, la escritura es experiencia de figuración y metamorfosis y más aún, metáfora múltiple del laberinto, del viaje, del fármaco: antídoto o veneno; desdoblamiento, río, dislocación y discurrir interminable, como lo propone Larrosa (1998) a propósito de la lectura en tanto contracara de la escritura. Así, lectura y escritura son operaciones dis-tintas que pulsan cuerdas semejantes (significación/interpretación) entre actores distintos o, cuando siendo otro y el mismo, lector y escritor fungen en momentos dis-continuos del mismo ejercicio de figuración del mundo. 
Ahora bien, las caracterizaciones hechas hasta aquí de la escritura muestran, de un lado, la centración del significante, que impone y reduce; y de otro, su descentración y dislocación, esto es, su tendencia a la apertura. En el primer nivel la escritura, de la misma manera que procede el diccionario, acota, cierra, impone el límite que favorece la significación y con ello la comunicación; en el segundo nivel, la misma escritura se desborda, se abre a la multiplicidad del sentido, se torna enciclopedia, como define Eco (1987) a ese universo de la semiosis ilimitada, es decir cuando "un signo se explica en su propio significado solamente remitiéndolo a un interpretante, el cual se refiere a otro interpretante y así sucesivamente hasta lo infinito" (Eco, 1973, p. 74).

En este sentido, queremos proponer que la escritura se torna línea de fuga, descentración, multiplicidad de voces; se teje de estratos, por lo que se constituye, de manera simultánea, en operación psicológica de abstracción, re-flexión, y modalidad de pensamiento, práctica social; textualidad y por tanto espacialidad y economía; dominio epistémico, dispositivo de poder-saber, pliegue, interiorización del afuera, dimensión ontológica: devenir. Así entendida la escritura, en su dimensión ontológica, se opone al diccionario, que "cierra" y se vuelca hacia la enciclopedia que "abre" el sentido.

De esta manera, la noción de enciclopedia que Eco utilizó para superar el concepto de código y de diccionario, sirve para referirse, en este caso, a la escritura como apertura, cuya fuente es, en términos de Bajtín (1989), el plurilingüismo o Heteroglosia del lenguaje, su estratificación interna tejida de "lenguajes de género; lenguajes de generaciones, de edades, de corrientes; lenguajes de autoridades; de círculos y modas pasajeros; lenguajes de los días, e incluso de las horas" (p. 81). Heteroglosia que se actualiza y desborda en todo el pensamiento posestructuralista que Deleuze-Guattari (2002) abordan en postulados de la lingüística y algunos regímenes de signos, capítulos IV y $\mathrm{V}$ de Mil mesetas.

Pero, por otro lado, y sin que signifique oposición o binarismo en relación con los rasgos anteriores; sino simultaneidad asimétrica, según puede deducirse de las ideas de los mismos autores, en Micropolitica y segmentariedad y Lo liso y lo estriado (pp. 214-233, 483-506), la escritura también organiza y produce territorialidades, cotos y cierres de su propio potencial expresivo, necesarios para lograr el efecto comunicativo derivado de la estratificación que producen los usos sociales específicos, entre ellos, las objetivaciones discursivas del mundo.

A este respecto, quizá resulte ilustrativa la idea de Bajtín (1993) en el sentido de que no hay lenguajes únicos, que toda significación es relativa, que es "sólo un momento, una gota en el río de la comunicación verbal, río ininterrumpido, así como es ininterrumpida la vida social misma, la historia misma" (p. 246). En esta lógica de razonamiento, la escritura como realización del lenguaje es fluido, discurrir, apertura que debe, en un momento dado, cerrarse para asegurar el entendimiento, esto es, para poder comunicar apelando, como único recurso, a la centración de la significación, "al cierre" siempre parcial y transitorio del lenguaje.

El lenguaje único no viene dado, sino que, de hecho, se impone siempre; y se opone al pluralismo real en todo momento de la vida del lenguaje $[. .$.$] es fuerza que tras-$ ciende ese plurilingüismo, poniéndole ciertas barreras que aseguran el máximo entendimiento recíproco que cristaliza en una unidad real, aunque relativa del lenguaje hablado (usual) predominante y del lenguaje literario, del 'lenguaje correcto' (Bajtín, 1989, p. 89).

Vista la escritura desde la óptica bajtiniana del lenguaje, lo que se pone de relieve es la lucha constante por la expresión que 
no acaba en la palabra expresada, sino en sus valoraciones, en los acentos, en la atmósfera social en la que se debaten las palabras, en el entramado profundo con la cultura. Y es allí en esa valoración que hace Bajtín (1982) de la cultura como fenómeno fronterizo, donde la escritura puede pensarse como práctica abierta, igualmente fronteriza que produce y hace parte constitutiva, no obstante, de esos "cierres" parciales pero estables de la heteroglosia social, que el mismo Bajtín denominara géneros discursivos. No obstante, (y por no ser el propósito de este trabajo, discernir sobre Bajtín) basta con señalar que una conceptualización de la escritura como actividad dialógica y heteroglósica podría sustentar la tesis de que esta es, ante todo, apertura, devenir, "río ininterrumpido", a la vez que un poderoso dispositivo de subjetivación.

\section{Escritura académica y poder disciplinario}

Pero si la escritura, como el lenguaje, procede mediante "cierres" parciales o relativos para contrarrestar la heteroglosia social, es porque se organiza de forma segmentaria. Y la segmentariedad, según Deleu-
ze-Guattari (2002), es una característica que nos compone como humanos: "el hombre es un animal segmentario. La segmentariedad es una característica específica de todos los estratos que nos componen. Habitar, circular, trabajar, jugar; lo vivido está segmentarizado espacial y socialmente" (p. 214).

En la línea de razonamiento de estos autores, los estratos que nos constituyen están formados por líneas de segmentariedad dura y flexible, que en nuestra perspectiva operan también en las prácticas de escritura y sus tipos textuales de los que el artículo científico sería expresión de segmentariedad dura, y cuya función va más allá de lo comunicativo al moverse, en los actuales contextos del capitalismo neoliberal, como dispositivo tecnocientífico y manifestación del poder disciplinario:

[...] el poder disciplinario es un poder discreto, repartido; es un poder que funciona en red y cuya visibilidad sólo radica en la docilidad y la sumisión de aquellos sobre quienes se ejerce en silencio. $\mathrm{Y}$ eso es, creo, lo esencial de la escena: el afrontamiento, la sumisión, la articulación de un poder soberano con un poder disciplinario. (Foucault, 2005, p. 39).

Esa naturaleza del poder disciplinario que señala Foucault, manifiesta quizá en toda la escritura, se hace más visible en las prácticas de escritura académica contemporánea como el artículo científico, caracterizado por su normatividad extrema, la rigidez de su estructuración, su espacialidad y textualización, así como en los mecanismos usados para regular y controlar su distribución y validación social, mediante mediciones estadísticas que llevan hasta la distopía ${ }^{1}$ la segmentariedad dura y hace del aparato normativo que regula el diseño, la producción y la distribución del discurso científico una esencia y de su realización en el artículo de divulgación científica un destino de docilidad y sumisión al que asistimos, en silencio, académicos e investigadores; tanto porque subjetivamos como deseable, necesaria y "científica", la manera de decir lo decible, que dicho régimen de enunciación establece; mientras participamos, así, de ese "poder anónimo, sin nombre, sin rostro, [...] repartido entre diferentes personas" (p. 38), a las que hoy llamaríamos, pares académicos, comunidad académica, socie-

1 La distopía es lo opuesto a la utopía. [...] La distopía plantea un mundo donde las contradicciones de los discursos ideológicos son llevadas a sus consecuencias más extremas. Mientras la utopía imagina un mundo donde las doctrinas se acoplen de manera armoniosa en el funcionamiento de las sociedades, la distopía, por su parte, toma la base del planteamiento utópico y lo lleva a sus consecuencias más extremas. El término distopía, como tal, surge a partir del vocablo utopía, creado por Tomás Moro, pero como su contrapartida, su antítesis, ("Distopía". En: Significados. com. Disponible en: https://www.significados.com/distopia/ Consultado el 1 de abril de 2018). 
dad del conocimiento; como porque, quizá estratégicamente, advertimos que docilidad y sumisión son moneda de compensación de nuestra propia manera de vivir neoliberal, que nos permite, entre otras múltiples posibilidades, participar de todas las formas del consumo cultural, producir los artículos, textos, discursos que el mercado científico, técnico y cultural demanda y recibir, en contrapartida, prestigio, reconocimiento, mejores ingresos, y en últimas, mantenernos en las formas distributivas de saber-poder con las que el mismo régimen de verdad sostiene su poder disciplinario:

[...] cierta forma terminal, capilar del poder, un último relevo, una modalidad mediante la cual el poder político y los poderes en general logran, en última instancia, tocar los cuerpos, aferrarse a ellos, tomar en cuenta los gestos, los comportamientos, los hábitos, las palabras; la manera, en síntesis, como todos esos poderes, al concentrarse en el descenso hacia los propios cuerpos y tocarlos, trabajan, modifican y dirigen lo que Servan llamaba las "fibras blandas del cerebro". (p. 59).
Así, podría decirse, la escritura académica, como también lo haría la escritura en sentido abierto - pues no se trata de decir que una sí y otra no lo hace-, toca los cuerpos, solo que en aquella, subsumida en el rígido carruaje normativo impuesto para la presentación de los informes científicos, el control es mayor, la forma termina por devorar el contenido o incluso por mimetizar el vacío conceptual en el rigor aparente de la norma. Es muy común entre los estudiantes y profesores universitarios que hacen o dirigen ejercicios de investigación, poner mayor acento en la precisión de las formas que impone la Asociación Americana de Psicología (APA) o el ICONTEC, que en el rigor del contenido. La pretensión de orientar la organización del texto que justifican estas normas, parece desdibujarse por la normatividad extrema y volátil (a tal punto que cada año se renuevan y modifican sobre aspectos que pueden juzgarse insustanciales para la comunicabilidad del saber científico); pero cuyo efecto es producir una suerte de control y dependencia continua de la escritura a lo que dictamine la norma y cierta experticia instrumental y operativa de la escritura misma, distinta en esencia a lo que esta constituye como devenir del pensamiento; pero que produce réditos en materia de aceptación y circulación de los textos "bien escritos", porque cumplen con las normas.

Por otra parte, si a este reduccionismo extremo de la escritura, se suman las exigencias editoriales de las revistas especializadas para que los artículos científicos se reproduzcan según las demandas del mercado, entonces el control disciplinario se ejerce de una manera más profunda, pues quien escribe, quien se somete a esos patrones de diseño, producción y distribución $^{2}$ no es un sujeto que se recrea con la escritura como estructura abierta, sino un trabajador, un profesor universitario-investigador-productor que se juega, en esas lógicas de producción discursiva, sus propias condiciones de existencia, el reconocimiento de su trabajo.

La condición que debe cumplir para lograr dicho reconocimiento es encajar en un modelo de escritura altamente estandarizada, hipernormalizada, homogénea, reproducible, ágil y fácil de ubicar en las vitrinas del consumo tecnocientífico. El

2 Dada la extensión del artículo, omitimos desarrollar en el texto aspectos relevantes del análisis del discurso que tendrían un enorme potencial para analizar las lógicas de la escritura académica y que podrían servir de cajas de herramientas para mostrar de manera muy precisa el funcionamiento de la escritura académica como dispositivo de control del saber/ poder y de la subjetividad misma. Al respecto, los enfoques de análisis multimodal (Kress y van Leeuwen, 2001) de quienes acogemos las categorías de diseño, producción y distribución del discurso; así como las apuestas metodológicas de Angenot, Fairclough y Van Dijk, entre otros reconocidos críticos del discurso, podrían ofrecer herramientas analíticas muy puntuales para mostrar empíricamente el funcionamiento del discurso a partir de sus gramáticas específicas, y sobre todo de sus pragmáticas. 
profesor- investigador-productor debe ahora elegir si acata y subjetiva como propia y natural la norma del diseño de escritura y muestra la productividad requerida, que se traduce en cifras de artículos indexados; o si, por el contrario, desacata las normas y elije la invisibilización, la subalternización, el silencio y aún la pérdida del empleo, si se torna improductivo, insumiso, incompetente. Así, la abstracción aparente de la norma cubre la superficie del cuerpo que la experimenta, y a veces su poder de subjetivación llega a ser tan extremo que ya no podemos advertir distancias entre la exterioridad que la impone y la subjetividad que la proyecta como propia.

Escritura académica y dispositivo

Pero si se llama la atención sobre el poder disciplinario que opera en la escritura académica, no es solo para destacar la disposición a obedecer - por las múltiples razones que pudieran enumerarse- de quienes la producimos o padecemos; sino porque en dicha práctica escritural se ponen en juego varios aspectos del dispositivo tecnocientífico:

Es claro que en este dispositivo no sólo está en juego un régimen de verdad en el cual se concibe el texto académico como un producto de consumo, sino también, el peso del estatuto científico y de ciertas gramáticas disciplinares que, en el marco de la modernidad occidental, han estado orientadas hacia la especialización, el objetivismo, la neutralidad y el rigor dado, en este caso, por la aplicación de un método enfocado en la constatación empírica y la medición. (Ortiz, 2015, p. 216).

En tanto dispositivo tecnocientífico, es un mecanismo de estimulación laboral que, señala Ortiz (2015), funciona en una red de relaciones en las que se articulan los estímulos académico-laborales traducidos en puntos salariales, la visibilización de la productividad de la universidad a la que se adscribe el profesor investigador, su proyección en la comunidad a través de mecanismos de verificación y visibilización como las revistas indexadas, las redes y bases de datos especializados, el CvLAC, los índices bibliométricos y el impacto directo en los procesos de Acreditación de Alta Calidad de las instituciones que tienen, justamente, en la productividad su

[...] mayor indicador asociado al "desarrollo" que equipara el conocimiento con cualquier otro producto de consumo. Se trata de un discurso que ha estado condicionado, de un lado, por relaciones de saber y poder procedentes de una racionalidad instrumental cientificista, y, por otro, por las reglas competitivas del mercado. (p. 219).

Detrás de todo esto, está el aparato estatal en instituciones como Colciencias, el Sistema Nacional de Ciencia y Tecnología SNCyT, el Departamento Nacional de Planeación que se constituyen en las agencias de producción discursiva encargadas de instalar en el discurso académico "el modelo económico y social, en relación con la emergencia de una tecnología neoliberal de gobierno" ( $p$. 219), que en instancias internacionales diseñan y promueven organismos como la OCDE, el Banco Mundial, EL FMI; y a cuya cadena discursiva suman diariamente voces con un gran poder de centración, como "Capital humano" "Sociedad del conocimiento" "economía del conocimiento" que constituyen verdaderos deslizamientos doxáticos ${ }^{3}$ (Angenot, 1998, pp. 37-42) del discurso neoliberal para posicionar las lógicas del mercado como si fuesen de la naturaleza del conocimiento científico. Así, la escritura

3 En la teoría del Discurso Social, particularmente en el texto Interdiscursividades (1998), Angenot se refiere a los deslizamientos doxáticos como movimientos ostentatorios y superficiales del discurso hegemónico que buscan reposicionar ideas rechazadas u obsoletas bajo la apariencia de lo nuevo o de lo inevitable. Son trampas del discurso social mediante las cuales se posicionan "verdades" que satisfacen demandas de la hegemonía. 
académica, práctica tensada entre el aparato discursivo en su encuentro con las técnicas gubernamentales, es también emplazamiento estratégico del sujeto en torno del saber: «El "espacio de saber" construye un emplazamiento que depende del orden que plantean los sistemas de representación [...] El emplazamiento prefigura, entonces, la noción Foucaultiana de "enunciado"» (Perea, 2016, p. 45).

De esta manera, el dispositivo escritura académica funciona, en efecto, como la Red de relaciones que propone Foucault, tal como se señala en los párrafos precedentes. Pero también como la gran máquina para hacer ver y hacer hablar (Deleuze, 1995); de la manera en que el dispositivo tecnocientífico como mecanismo de gubernamentalidad lo requiere. Esto es, de esa manera particular, "científica", de ver y de decir "el saber", manifiesta en el artículo científico, como tipo textual dominante de las publicaciones académicas. Pues en sus enunciados se juega un sujeto discursivo emplazado en unas lógicas de enunciación, organizadas en torno de distintas relaciones y correspondencias, que van desde el orden retórico (tácticas y estrategias de enunciación) hasta las lógicas del mercado que disponen la durabilidad de los productos, sus patrones de diseño a los que nos referiremos más adelante, sus formas de circulación y, por supuesto, los procesos productivos en los que el escritor-investigador-productor es solo el operario de la gran máquina de enunciación través de la cual se subjetiva.

En este sentido, la escritura académica y su correlato más inmediato, el artículo científico, deja de ser función comunicativa para convertirse en dispositivo de gobierno.

El dispositivo, dice Agamben (2015), "nombra aquello en lo cual y por medio de lo cual se realiza una pura actividad de gobierno sin el menor fundamento en el ser. Por esto los dispositivos deben siempre implicar un proceso de subjetivación. Deben producir su sujeto." (p. 13). Dicho de otra manera, cuando escribir para publicar en revistas académicas es, ante todo, ajustarse a su aparataje normativo, el sujeto que allí produce no procede desde "adentro" hacia la exterioridad, sino desde la exterioridad que lo norma, lo subjetiva y lo hace decir como "debe" decirse.

\section{El dispositivo en el discurso social}

En el caso particular de la escritura académica como dispositivo tecnocientífico, quizá sea posible mostrarla en su condición discursiva, esto es, como parte misma del discurso social ${ }^{4}$ para precisar desde allí sus lógicas de funcionamiento.

Si afincamos el dispositivo en su dimensión puramente discursiva, podemos decir que este se nutre de funciones básicas del discurso social, entendido como

[...] todo lo que se dice y se escribe en un estado de sociedad, todo lo que se imprime, todo lo que se habla públicamente o se representa $[\ldots]$ los sistemas genéricos, los repertorios tópicos, las reglas de encadenamiento de enunciados que, en una sociedad dada, organizan lo decible lo narrable y opinable- $y$ aseguran la división del trabajo discursivo. (Angenot, 2010, p. 21).

En ese sentido, el discurso social, en tanto social, supone historicidad; posee ciertas características de hegemonía, legitimación y aceptabilidad (pp. 31-49), y cumple funciones derivadas o ancladas en estas características que hacen posible su flujo en lo social.

Si entendemos la hegemonía del discurso social, no solo como

\footnotetext{
$4 \quad$ La categoría Discurso Social es introducida por el sociocrítico canadiense Marc Angenot (2010), para señalar la condición del discurso como hecho social. Su cercanía con la episteme de Foucault y con la noción de dispositivo como discurso y red de relaciones, nos resulta sugerente para comprender desde el funcionamiento social del discurso, cómo opera el discurso académico en tanto que dispositivo tecnocientífico.
} 
lo que "se manifiesta con más fuerza o se dice en varios lugares" (p. 31), sino como el "conjunto de mecanismos unificadores y reguladores que aseguran a su vez la división del trabajo discursivo y un grado de homogenización de retóricas, tópicas y doxas transdiscursivas" ( $\mathrm{p}$. 31), entonces la escritura académica no es sino una forma de realización de ese discurso social centrada en las retóricas tópicas y doxas del saber científico, como un saber constituido históricamente y en el que se instalan también (justamente por su naturaleza social) los fetiches, tabúes, egocentrismos, etnocentrismos propios de los contextos de producción y cuya función es saturar y expandir, legitimar y controlar, sugerir y hacer hacer, producir lo social $y$ sus identidades y bloquear lo indecible (pp. 61-84), de suerte que el sentido último de un texto, cualquiera que este sea, no puede verse ni más acá ni más allá "del hecho de que tenga una función social y de que sea el vector de fuerzas sociales". (p. 74).

Así las cosas, el artículo científico en particular y la escritura académica en general, son formas de hegemonía que imponen aceptabilidad sobre lo que se dice y se escribe, y estratifican grados y formas de legitimidad (p. 66) que pasan necesaria- mente por la manera en que se lo dice, el lugar desde el que se enuncia, los fines que persigue y el público hacia el que se dirige (p. 75.)

Reconocidas estas circunstancias del enunciado científico como parte misma del discurso social, surge la posibilidad de resistirlo, por cuanto al hacer visibles esas circunstancias de la enunciación se comprende que los discursos se diseñan, producen y distribuyen de acuerdo con patrones específicos que son contingentes, que no son inamovibles y que se legitiman por estrategias también discursivas, retóricas de saturación de lo decible, de expansión, de control de performatividad y que favorecen cierta hegemonía, en este caso discursiva, y no tanto el estatuto científico de la "verdad" así expresada. El análisis por tanto de las matrices sociohistóricas en que se produce el discurso científico, permite descentrar sus normas de producción y proponer $\mathrm{o}$, a lo menos, intentar formas alternativas de resistir.

Tender los puentes, entonces, entre unas nociones de dispositivo en tanto mecanismo de poder y subjetivación y el discurso como constructo social, y situar en esa relación la divulgación científica y, en el caso particular que nos ocupa, el artículo científico, nos permite verlo no como la forma científica y "natural" de divulgar la ciencia como una forma de hegemonía discursiva con sus recursos retóricos de saturación, expansión legitimación, control y bloqueo de lo indecible, que no solo comunica "científicamente" la ciencia, sino que salvaguarda o perpetua herencias como el positivismo discursivo, sus doxas de objetividad, trasparencia y neutralidad, mientras disimula o enmascara su metamorfosis como mercancía.

El discurso como mercancía, dice Angenot (2010), "hace aparecer leyes cuasi económicas, procesos que constituyen una especie de avatar del marketing" (p. 80), que se manifiestan en:

- la fuerte competencia en el interior de los campos discursivos $[\ldots]$

- obsolescencia rápida ${ }^{5}$ de las formas ideológicas [...]

- tendencia a la especialización de los ideólogos y a su acantonamiento tras almenas bien definidas

- doble movimiento: búsqueda desenfrenada de la distinción, producción de ideología y simultáneamen-

\footnotetext{
5 Basta advertir que en la escritura de artículos académicos, tesis de grado y levantamiento de estados del arte en investigación, se pide que las referencias no sean anteriores a cinco años, lo que revela una valoración bastantea arbitraria pero funcional para las lógicas del consumo, que considera ese tiempo el límite de la "vida útil" del producto.
} 
te multiplicación de formas vulgarizadas susceptibles de ser asimiladas con bagaje cultural mínimo, aparición en todos los campos de lo que se lee rápido y de lo que se comprende rápido,

- fenómeno de la falsa novedad y de la revolución previsible como formación de compromiso (p. 81).

Cada una de estas características pudieran advertirse no solo en las publicaciones académicas, sino de manera particular en las vidas de quienes escriben para ellas. Sabemos, por ejemplo, de los efectos que la exigencia de publicaciones producen entre profesores e investigadores universitarios, compelidos a competir por los puntos salariales y la propia estabilidad en los empleos, así como de la emergencia de figuras de poder que determinan lo pensable y decible en las publicaciones académicas, cada vez más restringidas y controladas, mientras, paradójicamente se ejerce presión desde la instituciones universitarias para publicar y asegurar así los índices de productividad que el sistema de la calidad reclama, aunque mucho de lo publicado sea, en efecto, materia de consumo fácil, comprensión rápida $\mathrm{y}$ falsa novedad.
Escritura académica y subjetivación: a manera de coda introspectiva

Entonces, la escritura académica dispositivo tecnocientífico, no solo se vuelca en las redes del consumo y la mercantilización, sino que en su forma más dominante, el artículo científico, pareciera aferrarse a la herencia más cerrada del positivismo metodológico que trastrueca el rigor en rigidez, la objetividad en supresión del sujeto (se insistió durante mucho tiempo hasta naturalizarlo como un principio de objetividad, el que no se escribiera en primera persona en ningún artículo científico, como si saltar a la tercera persona o a las trampas del "se" fuera suficiente recurso para anular al sujeto de la enunciación.

Y, por el mismo camino, Se hizo de la neutralidad de la ciencia, desideologización y ceguera política; reducción del conocimiento científico a medición, comprobación y experimento y, más aún, se dio por sentado que escribir de esa manera, dentro de los límites y exigencias del formato es la forma natural y lógica de divulgar los avances científicos, cuando lo que se esconde allí es una manifestación de etnocentrismo de la escritura y una imposición autoritaria que, según lo determina la APA, debe cumplirse para poder "figurar" a partir de la homoge- nización de las formas del discurso académico en los listados reconocidos de las publicaciones internacionales.

Alguien, sin embargo, podría argumentar que estas herencias están ya superadas y que ningún investigador serio, sobre todo en el campo de las humanidades y las ciencias sociales caería en estos desatinos; pero, basta echar un vistazo al discurso científico a sus lógicas de diseño, producción y distribución (Kress \& Leeuwen, 2001) para advertir allí, en su manifestación dominante: el artículo científico, las supervivencias de un positivismo que no es solo método sino sustancialmente un lenguaje que diseña y produce verdad, que mueve estrategias $\mathrm{y}$ tácticas argumentativas saturadas del espíritu demostrativo-comprobatorio; un diseño discursivo que mide, matematiza y espacializa lo decible, al determinar el número de referencias que, como citas de autoridad con valor comprobatorio, ha de tener lo dicho, lo que lleva a Estela Quintar (2009) a preguntarse “ ¿dónde queda la palabra autorizada del sujeto/autor?, ¿qué espacio de palabra propia tiene tanta des-autorización?; ¿por qué desautorizar al autor con tanta autorización externa a él y su pensar?" (pp. 119-133); y que monitorea, luego con herramientas estadísticas la distribución discursiva mediante el rastreo bibliométrico y "com- 
prueba", igualmente, con indicadores de frecuencia como el de Hirsch 6 , la validez del enunciado "científico" publicado.

El diseño cerrado del artículo científico define con rigidez absoluta la arquitectura del texto, no solo su espacialidad de superficie que impone un número limitado de páginas, de palabras y citas, sino los segmentos discursivos y su ordenamiento en la geografías del texto: muchas publicaciones insisten en el formato canónico que establece las partes estructurantes: el resumen, que en muchos caso no debe superar las 150 palabras; la introducción, que presenta el problema y su encuadre teórico; el método; los resultados obtenidos; y la discusión (según la sigla en inglés IMR\&D).

En esas cuatro secciones, en sus compartimientos cerrados, se obliga a habitar el discurso abierto, más heteroglósico de las humanidades y los estudios sociales, y aún los de los estudios literarios que, para pervivir, han abandonado su forma más natural y proteica de aproximación al fenómeno literario, cual es el ensayo, virtualmente desterrado de las publicaciones especializadas. Ese exceso de positivismo que bien puede leerse mejor como pragmatismo utilitario, desterró el encanto de la escritura ensayística como forma ideal, verdaderamente creativa de re-crear la obra literaria.

Un discurso cuya naturaleza tiende más a la apertura que al cierre, un discurso que no busca la síntesis del experimento y cuya función no es informativa sino ideacional, heurística, creativa (Halliday, 1979, pp. 67-70); un discurso que es sustancialmente un devenir, esto es, una figuración constante del mundo objetivo que moldea la palabra; pero que debe someterse al cerco establecido, a unos patrones de diseño que parecieran atender más a la economía del consumo.

Los artículos científicos parecieran diseñados para satisfacer las lógicas de la mercancía, adecuados para posicionarse en esa suerte de vitrinas del conocimiento en las que se han convertido las revistas indexadas y más allá de ellas, en las bases de datos especializadas que, como verdaderas marcas corporativas de la producción académica, exhiben en las ventanas de búsqueda virtuales (los centros comerciales del discurso científico), los nuevos productos siempre fungibles, volátiles como toda mercancía a los que el investigador profesional accede previo el pago de franquicias para consultarlos, o deberá consolarse, como quien mira en los bazares, con las vistas parciales, segmentadas des- articuladas del producto, mientras atrás de esos sitios de exhibición, en las trastiendas del mercado, continúa la incesante máquina de producción discursiva.

En ella, está instalado ese nuevo tipo de trabajador, el profesor-investigador que, particularmente en el sector privado, debe no solo atender las funciones de docencia, extensión y aun de administración de la empresa educativa, sino, además, producir un determinado número de artículos indexados por año, por período de gestión académica y de cuya circulación en ese mercado depende su propia continuidad en el empleo y la mejora de sus ingresos al traducir en puntos salariales cada nuevo producto.

Es una exigencia que le hace la institución a la que está adscrito, pues para esta, cada artículo publicado es un indicador claro de la "productividad científica", una matematización de la escritura, "una prueba objetiva" que suma al reconocimiento de la calidad por la que compite en las lógicas del mercado educa-

$6 \quad$ Creado por Jorge Hirsch en el año 2005, el índice h permite detectar los investigadores más destacados de una disciplina. No obstante, no sirve para comparar investigadores de diferentes disciplinas, no tiene en cuenta la calidad de las revistas donde se publica y perjudica los autores que publican poco, aunque sus documentos sean muy relevantes y ampliamente citados. Un investigador tiene un índice $h$ si ha publicado $h$ trabajos con al menos $h$ citas cada uno (Índices de impacto Índice H. En https://biblioguias.biblioteca. deusto.es/c.php?g=155487\&p=1099760). 
tivo toda la institución universitaria.

En este sentido, decíamos unas líneas arriba, la escritura académica y particularmente el formato del artículo científico, sus lógicas de diseño, producción y distribución se tornan distópicas, que equivale a decir hipernormalizadas, cerradas, verdaderas líneas segmentales duras que revelan las contradicciones ideológicas de un diseño discursivo, que particularmente en los dominios de las humanidades, los estudios sociales, la literatura y el arte, hace del sometimiento del cuerpo a través de la escritura una forma extrema de disciplinamiento $\mathrm{y}$, si se quiere, de metamorfosis monstruosa de la subjetividad como se pone en evidencia en la expresión de una investigadora chilena, que en un congreso internacional de investigación en ciencias sociales manifestara, enarbolando la voz, que se sentía como una gallina enjaulada poniendo huevos, para referirse de esa manera a la exigencia de la universidad en la que trabaja, a publicar un mínimo de tres artículos en revistas indexadas por año, como indicador determinante de su desempeño académico y condición misma de conservación del empleo.

Este dato, en el que el gallinero es metáfora de la universidad y recogido además en el escenario de privilegio para el cruce de comunicaciones académicas, como es el congreso de especialistas, pone en evidencia que la universidad funciona como una "máquina cognitiva para la producción capitalista" (Martínez, 2010, p. 96), no solo porque produce productores desde el dispositivo pedagógico-didáctico-curricular que forma en las profesiones y ahora en el "emprendimiento", sino porque actúa en la subjetividad de quien se forma, y de sus formadores a través del managament, pues, en el caso particular de la escritura académica hay, en efecto, unos patrones de gestión, un efectivo conjunto de disposiciones para la producción, suficientemente normado y controlado (APA, ICONTEC) que determina cómo ha de hacerse el producto $\mathrm{y}$, en consecuencia, como debe subjetivarlo el trabajador-profesor-investigador-productor.

Podríamos partir de la idea de que la gestión o managament constituye un conjunto de prácticas por las que el capital, como forma de las relaciones sociales de la modernidad, organiza la fuerza de trabajo y el proceso de trabajo mismo a los fines de la acumulación capitalista. Con esta definición abordaríamos el managament como cuerpo de saber acerca del trabajo y conjunto de disposiciones de poder que se despliegan sobre los sujetos que trabajan. En términos de cierta interpretación de la propuesta Foucaultiana diríamos entonces que el managament es una tecnología de poder, es decir, una tecnología que determina la conducta de los individuos imponiéndoles finalidades y objetivos. Podemos agregar -desde mi punto de vistaque, tomado así, constituye un conjunto de prescripciones heteroimpuestas sobre los individuos en situación de trabajo; prescripciones descendentes, efectivamente totalizantes. (Zangaro, 2011, p. 16).

En otro sentido y para cerrar, cabe agregar, también, que escribir "artículos científicos" en y desde las humanidades y los estudios sociales produce aunque sea solo en este escrito sobre la escritura académicacierta suerte de contradicción performativa (y aquí saltamos a la primera persona del plural que siempre somos y seremos), y que hace que debamos ocuparnos en este instante en que la escritura se torna objeto de la escritura, en revisar si completamos ya el número de citas y en prever las líneas de corte para achicar el texto y mantenernos dentro de las exigencia que el artículo académico demanda $y$, más aún, que nos esforcemos por mantenernos, aunque sin lograrlo a cabalidad, en los bordes mismos del modo de decir académico sino romperlo, para no expulsarnos a nosotros mismos del dispositivo.

Por fortuna, el mismo Platón solo pudo decir en favor de la memoria afincada en la oralidad y contra la escritura, escribien- 
do y, paradójicamente, ese gesto salvó para la memoria misma lo que dijo.

Con demasiada frecuencia, ocurre que decir un cuerpo, objetivarlo en los discursos académicos, se haga por escisión del propio sujeto que lo enuncia, como si este fuese otro sujeto, distante, ajeno al fenómeno que describe, que explica, que interpreta, como por ejemplo, cuando mucho se dice de la condición neoliberal, del dispositivo, de la subjetivación como externalidades discursivas y no como el "adentro del afuera", como esas condiciones existenciales propias de quien sobre ellas escribe y cuyo olvido aparente no es sino una pervivencia, sin duda, de nuestra manera de mirar positivista.
Quizá pueda decirse, a manera de conclusión esperanzada, que nos asiste a todos los investigadores y académicos comprometidos con el sostenimiento y difusión de la investigación académica, el deber de indagar más en las formas legitimadas de la escritura, el deber de reflexionar detenidamente sobre su mecanismos de producción y trayectorias sociohistóricas para comprenderla como manifestación del discurso social, para interpelar y resistir desde los dominios mismos de la escritura la excesiva centración de los formatos.

\section{Epilogo narrativo}

\section{"EL GRAFÓGRAFO}

Escribo. Escribo que escribo. Mentalmente me veo escribir que escribo y también puedo verme ver que escribo. Me recuerdo escribiendo ya y también viéndome que escribía. Y me veo recordando que me veo escribir y me recuerdo viéndome recordar que escribía y escribo viéndome escribir que recuerdo haberme visto escribir que me veía escribir que recordaba haberme visto escribir que escribía y que escribía que escribo que escribía. También puedo imaginarme escribiendo que ya había escrito que me imaginaría escribiendo que había escrito que me imaginaba escribiendo que me veo escribir que escribo".

Elizondo, S. El grafógrafo

\section{Referencias}

Angenot, M. (1998). Interdiscursividades. Córdoba: Universidad Nacional de Córdoba.

Angenot, M. (2010). El discurso Social. Los límites históricos de lo pensable y lo decible.

Argentina: Siglo XXI.

Bajtín, M. (1982). Estética de la Creación Verbal. México: Siglo XXI.

Bajtín, M. (1989).Teoría y estética de la novela. Madrid: Taurus.

Bajtín, M. (1993). ¿Qué es el lenguaje? En A. Silvestri \& G. Blanck (Eds.), Bajtin y Vigotski: la organización semiótica de la conciencia (pp. 217-244). Barcelona: Anthropos. 
Ball, S.J. (2003). Profesionalismo, gerencialismo y performatividad. Educación y Pedagogía, (37), pp. 87-104.

Butler, J. (1993). Cuerpos que importan. Sobre los límites materiales y discursivos del «sexo». Buenos Aires: Paidós.

Deleuze, G. (1995). Deseo y placer. (J. Sáez, Trad.). Archipiélago. Cuadernos de crítica de la cultura, (23), 12-20.

Deleuze, G. y Guattari, F. (2002). Mil mesetas. Valencia: Pretextos.

Deleuze, G. (s.f.). La literatura y la vida. Recuperado de http://estafeta- gabrielpulecio.blogspot.com. co/2007/11/deleuze-2.html

Eco, U. (1973). Signo. Colombia: Labor.

Eco, U. (1987). Lector in fabula. Barcelona: Lumen.

Elizondo. S. El grafógrafo. Disponible en http://www.lamaquinadeltiempo.com/elizondo/grafografo. html

Foucault, M. (1983). El discurso del poder. México: Folios.

Foucault, M. (2005). El poder psiquiátrico. México: FCE.

Halliday, M.K. (1979). El lenguaje como semiótica social. México: FCE.

Kress, G. y van Leeuwen, T. (2001). Multimodal Discourse: The modes and Media of

Contemporary Communication. London: Arnold.

Martínez, J. E. (2010). La Universidad productora de productores: entre biopolitica y subjetividad. Bogotá: Universidad de la Salle.

Ong, W. (1999). Oralidad y escritura. Tecnologías de la palabra. Bogotá: FCE.

Ortiz, M.N. (2015). Incidencias del dispositivo tecno científico en la escritura de las humanidades en Colombia. Nómadas, (42), 115-125.

Perea, J.A. (2016). Michel Foucault: Vocabulario de nociones espaciales. Bogotá: Universidad Distrital Clacso. 
Quintar, E. (2009). Pedagogía de la potencia y didáctica no parametral. Entrevista con Estela Quintar. Revista Interamericana de Educación de Adultos, 31(1), 119-133. Recuperado de http://www. redalyc.org/articulo.oa?id $=457545096006$

Rama, A. (1984). La ciudad letrada. Montevideo: Fundación Internacional Ángel Rama.

Zangaro, M. (2011). Subjetividad y trabajo. Una lectura Foucaultiana del Management. Buenos Aires: Ediciones Herramienta. 